\title{
Novel FAM126A mutations in hypomyelination and congenital cataract disease
}

\author{
M. Traverso ${ }^{\text {a }}$, S. Assereto ${ }^{\text {a }}$, E. Gazzerro ${ }^{\text {a }}$, S. Savasta ${ }^{\text {b }}$, E.M. Abdalla ${ }^{c}$, A. Rossi ${ }^{\text {d }}$, S. Baldassari ${ }^{\text {a }}$, \\ F. Fruscione ${ }^{a}$, G. Ruffinazzi ${ }^{\text {b }}$, M.R. Fassad ${ }^{c}$, A. El Beheiry ${ }^{\mathrm{e}}$, C. Minetti ${ }^{\text {a }}$, F. Zara $^{\text {a }}$, R. Biancheri $^{\mathrm{a}, *}$ \\ a Department of Neuroscience, Istituto Giannina Gaslini, Genova, Italy

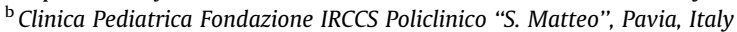 \\ 'Medical Research Institute, Alexandria University, Egypt \\ d Pediatric Neuroradiology, Istituto Giannina Gaslini, Largo G. Gaslini, 5, 16147 Genova, Italy \\ ${ }^{\mathrm{e}}$ Faculty of Medicine, Alexandria University, Egypt
}

\section{A R T I C L E I N F O}

Article history:

Received 18 August 2013

Available online 30 August 2013

Keywords:

Myelination

White matter disorder

Cataract

FAM126A gene

\begin{abstract}
A B S T R A C T
Hypomyelination and congenital cataract (HCC, OMIM \#610532) is a rare autosomal recessive disorder due to FAM126A mutations characterized by congenital cataract, progressive neurologic impairment, and myelin deficiency in the central and peripheral nervous system. We have identified two novel mutations in three affected members of two unrelated families. Two sibs harbouring a microdeletion causing a premature stop in the protein showed the classical clinical and neuroradiologic HCC picture. The third patient carrying a missense mutation showed a relatively mild clinical picture without peripheral neuropathy. A residual amount of hyccin protein in primary fibroblasts was demonstrated by functional studies indicating that missense mutations are likely to have less detrimental effects if compared with splice-site mutations or deletions that cause the full-blown HCC phenotype, including peripheral nervous system involvement.
\end{abstract}

(c) 2013 Elsevier Inc. All rights reserved.

\section{Introduction}

Hypomyelination and congenital cataract (HCC, OMIM \#610532) is a rare autosomal recessive disorder characterized by congenital cataract, progressive neurologic impairment, and myelin deficiency in the central and peripheral nervous system $[1,2]$. FAM126A gene (OMIM *610531; previously named DRCTNNB1A) encoding a novel neuronal protein, hyccin, is responsible for the disorder $[1,3]$. The phenotype ranges from a severe early-onset neurologic impairment to a relatively mild clinical picture. Peripheral neuropathy has been reported in all patients carrying splice-site mutations or deletions $[2,4,5]$, whereas it was absent in the only patient harbouring a missense mutation [1,2]. Brain magnetic resonance imaging (MRI) typically shows the combination of a diffuse hypomyelination with prominent T2 hyperintensity and $\mathrm{T} 1$ hypointensity in the periventricular and deep cerebral white matter [6,7].

We describe the clinical, neuroradiologic, and molecular findings in three affected members of two unrelated families segregating two novel mutations.

\footnotetext{
* Corresponding author. Address: Department of Neuroscience, Istituto G. Gaslini, Largo G. Gaslini 5, 16147 Genova, Italy. Fax: +39 010381303.

E-mail address: roberta@biancheri.com (R. Biancheri).
}

\section{Patients and methods}

The patients underwent clinical, neurophysiological, neuroradiologic and molecular studies. Functional effect of mutations have been characterized on patients' fibroblasts by Immunoblot analysis.

\subsection{Cell lines}

Primary cutaneous fibroblasts were isolated from two mutated patients and three healthy individuals and maintained in culture as previously described [8].

\subsection{Subcellular fractionation and Western blot analysis}

Fibroblasts were harvested in ice cold PBS, collected by centrifugation at $1280 \mathrm{rpm}$ for $8 \mathrm{~min}$, and allowed to swell in hypotonic buffer ( $5 \mathrm{mM}$ Tris- $\mathrm{HCl}$, pH 7.5, $1 \mathrm{mM} \mathrm{MgCl}, 1 \mathrm{mM}$ EGTA, $0.1 \mathrm{mM}$ EDTA) containing freshly added protease inhibitors (1 mM phenylmethylsulfonyl fluoride/PMSF, $0.5 \mathrm{mM}$ trypsin inhibitor and $0.05 \%$ leupeptin) for $30 \mathrm{~min}$ on ice. Lysis is achieved by passing through a 26 gauge. Cells were then centrifuged at $2000 \mathrm{~g}$ at $4{ }^{\circ} \mathrm{C}$ for $5 \mathrm{~min}$. The supernatant was removed and then centrifuged at 56,000g at $4{ }^{\circ} \mathrm{C}$ for $30 \mathrm{~min}$. The supernatant, containing the cytoplasmic 
fraction, was separated from the pellet, containing the membrane fraction. Protein concentrations of the cytoplasmic and membrane fractions were determined by the Bradford assay (BioRad).

\subsection{Western blot analysis}

For Western blot analysis, $20 \mu \mathrm{g}$ and $8 \mu \mathrm{g}$ of cytoplasmatic and membrane subcellular fraction respectively was loaded on $10 \%$ SDS-polyacrylamide gels and electrophoresed and transferred to Immobilon-P (Millipore) using the wet electrophoretic transfer procedure. After blotting the membrane was incubated for $2 \mathrm{~h}$ with primary antibodies (polyclonal antibody against D-Hyccin (Santa Cruz) 1:500; polyclonal antibody against GAPDH (Santa Cruz) 1:500) followed by incubation with the corresponding horseradish peroxidase-conjugated. The bands were detected by ImageQuant 350 (GE HealthCare).

\section{Results}

\subsection{Family \#1}

Patients \#1 and 2 are Egyptian female sibs. Parents are consanguineous (see pedigree, Fig. 1).

The proband is a 8-year-old girl born at term after uneventful pregnancy and normal delivery. Bilateral congenital cataract was depicted soon after birth and she underwent ocular surgery at 6 months. The early development was normal, but she was not able to stand at the end of the first year of life. She was able to walk with support at one year, but never acquired the ability of walking unsupportedly. She never suffered from seizures. The last neurological examination showed nystagmus, strabismus, truncal hypotonia with muscle weakness, wasting and spasticity of the lower limbs, scoliosis, and mental retardation. Neurophysiological studies showed sensorimotor peripheral neuropathy with myelin and axon involvement. Brain MRI showed diffuse supratentorial hypomyelination with areas of more pronounced T1-hypointensity and T2-hyperintensity, consistent with increased water content in these regions (Fig. 2).

The younger sister is a 5-year-old girl born at term after uneventful pregnancy and normal delivery. The clinical picture and disease course are similar to those described for the older sister. She underwent ocular surgery for bilateral congenital cataract at age of 5 months. She is not able to walk without support. The last neurological examination showed nystagmus, strabismus, truncal hypotonia with muscle weakness, wasting and spasticity of the lower limbs, and mental retardation. Neurophysiological studies showed sensorimotor peripheral neuropathy with myelin and axon involvement.

Brain MRI features were similar to those described in the elder sister (not shown).

\subsection{Family \#2}

Patient \#3 is a 14-month-old girl of Moroccan origin born at term after uneventful pregnancy and normal delivery. Parents are consanguineous. Five members of the family showed congenital cataract and progressive neurologic impairment. Two of them died at 47 and 50 years, respectively (see pedigree, Fig. 1). Clinical and molecular assessment of these subjects were not possible.

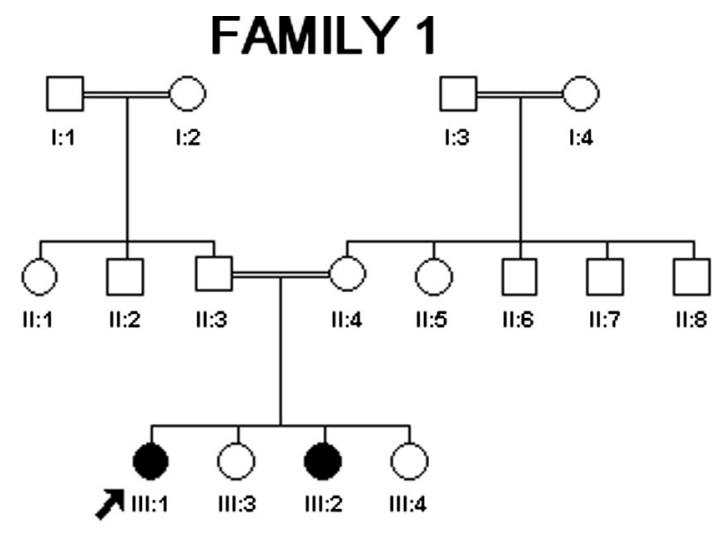

FAMILY 2

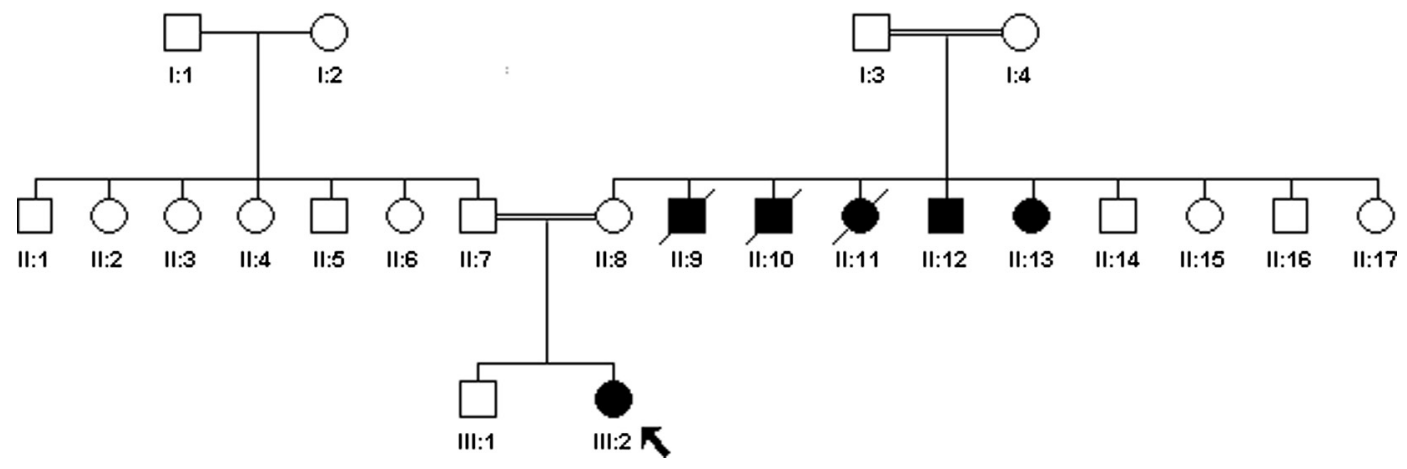

Fig. 1. Families' pedigrees. 


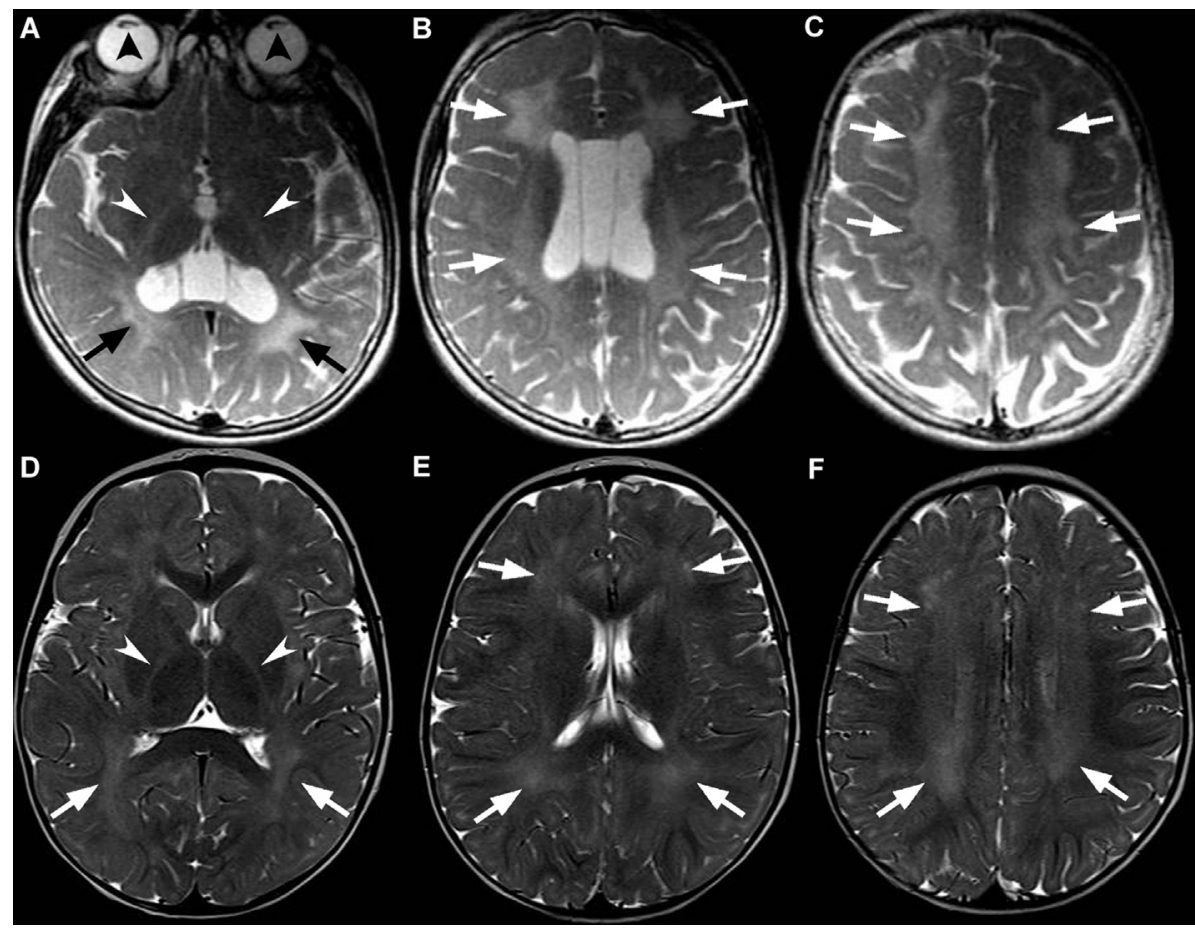

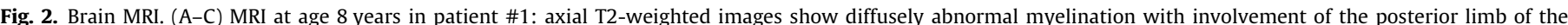

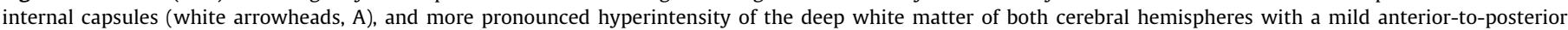

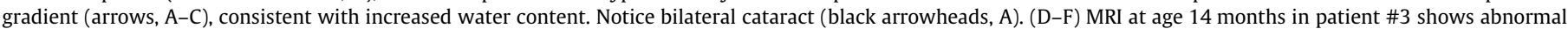

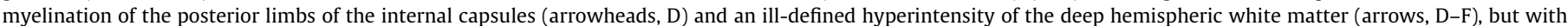
almost complete preservation of subcortical myelin. Notice that myelination of the subcortical fibers is still physiologically incomplete at this age.

The girl presented with bilateral congenital cataract at birth and underwent ocular surgery at 2 months. Due to the presence of congenital cataract she was referred to us for neurological evaluation, as scheduled by our national health protocol. Neurological examination showed normal behaviour for age, mild muscle hypotonia, brisk tendon reflexes, ability of walking with support. She never suffered from seizures. On the basis of the association of congenital cataract, soft neurological signs, and family history we suggested to perform brain MRI that showed diffuse supratentorial hypomyelination (Fig. 2). Nerve motor and sensory conduction velocities studies (sural, common peroneal and tibial nerves) were normal.

\subsection{Genetic and functional analysis}

Mutational screening of FAM126A was performed as described [1]. Two novel mutations were identified in these families: patient \#1 and 2 (family 1) showed a microdeletion c.100-101delAA which causes a premature stop (p.Lys33Glufs $* 17$ ) in the protein, thus significantly impairing protein structure; patients \#3 (family 2) showed the homozygous variant c.169T > C determining the substitution of cysteine with arginine in position 57 of the protein (p.C57R).

Hyccin protein levels were hence quantified in primary fibroblasts isolated from patient \#3, from two age-matched healthy controls and from a patient, previously characterized, carrying a p.L53P mutation [1]. When compared to the controls, the p.C57R mutant displayed a $40 \%$ reduction in hyccin protein levels, while the p.P53L mutant was decreased of approximately $70 \%$ (mean \pm SE, $n=3$ experiments) (Fig. 3).

\section{Discussion}

In this study we have described three additional HCC patients carrying novel mutations. Hypomyelinating white matter disorders represent the single largest category among undiagnosed genetic leukoencephalopathies [7,9]. HCC has been firstly reported in 2006 [1]. To date, 22 patients and 8 different mutations have been reported in the literature $[1,2,4,5]$. Interestingly, all mutated subjects originate from Southern Italy, Morocco, Turkey, and Israel. We previously suggested a founder effect, on the basis of a common haplotype found in four unrelated patients [4]. The present families originate from Morocco and Egypt, thus confirming that HCC, though rare, is not uncommon in the Mediterranean area.

The two Egyptian siblings showed the classical HCC form characterized by bilateral congenital cataract, neurologic impairment with inability of walking unsupportedly, and peripheral neuropathy. Brain MRI showed the peculiar HCC features, i.e. the presence of diffuse hypomyelination combined with areas of prominent T2 hyperintensity and T1 hypointensity. The microdeletion carried by these subjects causes a premature stop in the protein, thus significantly impairing protein structure, similarly to the previously reported patients with the classical HCC form and absence of the protein at functional studies [1].

On the other hand, the last patient of this study showed bilateral congenital cataract, soft neurological signs and a positive, although without specific diagnosis, family history. The presence of diffuse supratentorial hypomyelination on brain MRI raised the diagnostic suspicion of HCC, confirmed by molecular analysis. Nerve conduction velocity studies were normal. Interestingly this is the second HCC patient in whom peripheral nervous system is not involved. She carried a missense mutation and displayed a residual amount of hyccin protein in primary fibroblasts similarly to the previously described subject carrying a p.L53P mutation without peripheral nerve involvement [1,2]. These results further support the hypothesis that missense mutations are likely to have less detrimental effects, preserving some neurological functions, if compared with splice-site mutations or deletions that cause the full-blown HCC phenotype, including peripheral nervous system involvement. Notably both the p.L53P and p.C57R mutations are 
A

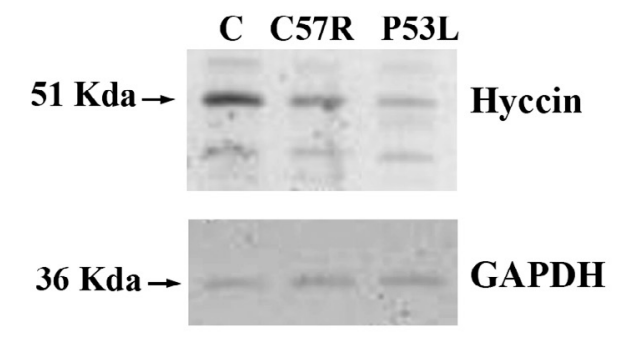

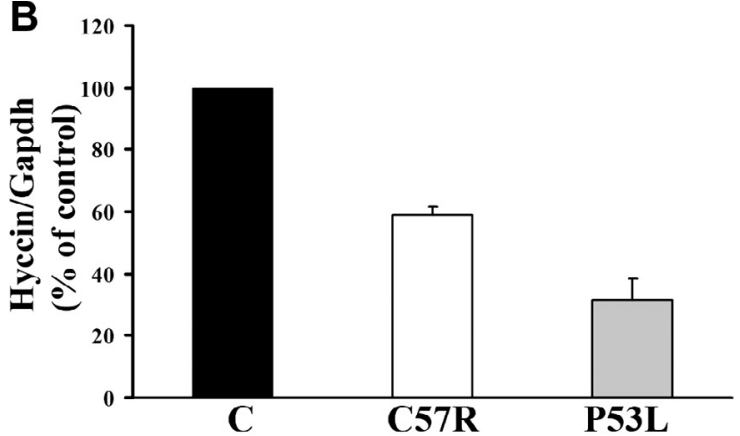

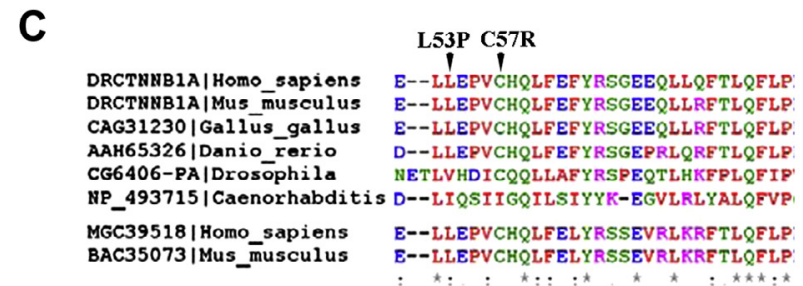

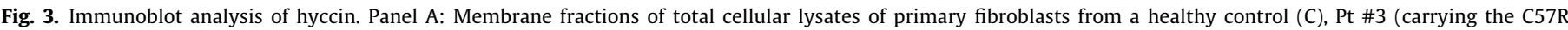

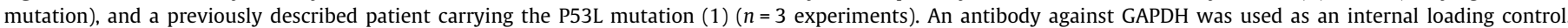

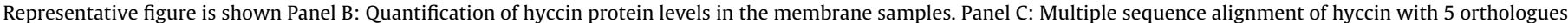

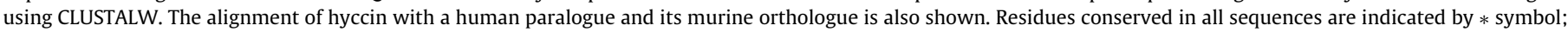
conserved and semi-conserved substitutions are indicated by ": " and ". " symbols, respectively. The L53P, and the C57R mutations are indicated with an arrowhead.

included in hyccin central domain (aminoacid 20 to aminoacid 330 ) which is in common to the members of the hyccin protein family and is also highly conserved throughout species.

Although hyccin specific mechanisms of action are still unknown, its primary expression in cells of the neuronal lineage suggests its involvement in the neuron-to-glia crosstalk which regulates the onset of myelination and/or myelin maintenance [3].

The present study demonstrates that the awareness of clinical and neuroradiologic features of HCC is crucial to properly address diagnostic work-up and give appropriate genetic counseling. Indeed, the association of the typical clinical and MRI features of HCC in the two sibs prompted us to directly analyze FAM126A gene, whereas in the other patient neurological assessment was done because of the presence of congenital cataract and family history. In this patient, brain MRI showed isolated hypomyelination without the areas of prominent $\mathrm{T} 2$ hyperintensity and $\mathrm{T} 1$ hypointensity, that are considered to be highly suggestive of HCC allowing distinction between HCC and other hypomyelinating disorders $[7,9]$. However, this is not surprisingly, due to the young age of the patient who is the youngest subject reported so far in the literature.

In conclusion, we have described novel mutations in additional unrelated patients with HCC, further defining genotype-phenotype correlations and reinforcing the hypothesis that a residual amount of hyccin protein may preserve some neurological functions.

\section{Acknowledgments}

This work has been supported by the ELA Foundation (Grant No. ELA 2009-045C3 to F.Z. and Grant ELA 2009-032I4 to C.M.).

The patient samples was obtained from the "Cell Line and DNA Biobank from Patients Affected by Genetic Diseases" (G. Gaslini Institute)-Telethon Network of Genetic Biobanks (Project No. GTB12001). This work was partially supported by grants from the Italian Health Department 'Finanziamento Cinque per mille e Ricerca Corrente' (and FP7-HEALTH-LeukoTreat No. 241622).

\section{References}

[1] F. Zara, R. Biancheri, C. Bruno, L. Bordo, S. Assereto, E. Gazzerro, F. Sotgia, X.B Wang, S. Gianotti, S. Stringara, M. Pedemonte, G. Uziel, A. Rossi, A. Schenone, P. Tortori-Donati, M.S. van der Knaap, M.P. Lisanti, C. Minetti, Deficiency of hyccin, a newly identified membrane protein causes hypomyelination and congenital cataract, Nat. Genet. 38 (2006) 1111-1113.

[2] R. Biancheri, F. Zara, C. Bruno, A. Rossi, L. Bordo, E. Gazzerro, F. Sotgia, M. Pedemonte, S. Scapolan, M. Bado, G. Uziel, M. Bugiani, L.D. Lamba, V. Costa, A. Schenone, A.J. Rozemuller, P. Tortori-Donati, M.P. Lisanti, M.S. van der Knaap, C. Minetti, Phenotypic characterization of hypomyelination and congenital cataract, Ann. Neurol. 62 (2007) 121-127.

[3] E. Gazzerro, S. Baldassari, C. Giacomini, V. Musante, F. Fruscione, V. La Padula, R. Biancheri, S. Scarfi, V. Prada, F. Sotgia, I.D. Duncan, F. Zara, H.B. Werner, M.P. Lisanti, L. Nobbio, A. Corradi, C. Minetti, Hyccin, the molecule mutated in the leukodystrophy hypomyelination and congenital cataract (HCC), is a neuronal protein, PLoS One 7 (2012). e32180.

[4] R. Biancheri, F. Zara, A. Rossi, M. Mathot, M.C. Nassogne, C. Yalcinkaya, O. Erturk B. Tuysuz, M. Di Rocco, E. Gazzerro, M. Bugiani, R. van Spaendonk, E.A Sistermans, C. Minetti, M.S. van der Knaap, N.I. Wolf, Hypomyelination and congenital cataract: broadening the clinical phenotype, Arch. Neurol. 68 (2011) 1191-1194.

[5] M. Traverso, O.O. Yuregir, A. Mimouni-Bloch, A. Rossi, H. Aslan, E. Gazzerro, S. Baldassari, F. Fruscione, C. Minetti, F. Zara, R. Biancheri, Hypomyelination and congenital cataract: identification of novel mutations in two unrelated families Eur. J. Paediatr. Neurol. 17 (1) (2013 Jan) 108-111.

[6] A. Rossi, R. Biancheri, F. Zara, C. Bruno, G. Uziel, M.S. van der Knaap, C. Minetti, P. Tortori-Donati, Hypomyelination and congenital cataract: neuroimaging features of a novel inherited white matter disorder, AJNR Am. J. Neuroradiol. 29 (2008) 301-305.

[7] M.E. Steenweg, A. Vanderver, S. Blaser, A. Bizzi, T.J. de Koning, G.M. Mancini, W.N. van Wieringen, F. Barkhof, N.I. Wolf, M.S. van der Knaap, Magnetic resonance imaging pattern recognition in hypomyelinating disorders, Brain 133 (2010) 2971-2982.

[8] S. Assereto, O.P. van Diggelen, L. Diogo, E. Morava, D. Cassandrini, I. Carreira, W.P. de Boode, J. Dilling, P. Garcia, M. Henriques, O. Rebelo, H. ter Laak, C. Minetti, C. Bruno, Null mutations and lethal congenital form of glycogen storage disease type IV, Biochem. Biophys. Res. Commun. 361 (2) (2007 Sep 21) 445450.

[9] R. Schiffmann, M.S. van der Knaap, Invited article: an MRI-based approach to the diagnosis of white matter disorders, Neurology 72 (2009) 750-759. 